IDEAs IN ECRLGGY AND EVRLUTION 4: 11-13, 2011

doi:10.4033/iee.2011.4.2.c

(C) 2011 The Author. (C) Ideas in Ecology and Evolution 2011 Received 23 February 2011; Accepted 11 March 2011

\title{
Commentary
}

\section{A philosopher's view of theory: A response to Gorelick}

\author{
Mark Colyvan \\ Mark Colyvan (mark.colyvan@sydney.edu.ca), Sydney Centre for the Foundations of Science, A14 Main \\ Quadrangle, University of Sydney, Sydney, NSW, 2006, Australia
}

It is always good to see scientists engaging in philosophical reflection on the nature and practices of science. It was thus a delight to read Root Gorelick's (2011) paper in which he attempts to answer the very important question posed in the title: What is theory? Gorelick brings his scientific experience to this question and makes a great deal of progress on trying to distinguish theoretical science from the rest. To philosophers of science, this is gold. Philosophers take such philosophical reflections from scientists very seriously. After all, philosophy of science, as I see it, is in the business of understanding and systematising science as it is practiced. When the opportunity arises to read a thoughtful and clearly articulated account of what a working scientist considers to be the distinguishing features of theoretical science, I for one sit up and take notice. I take notice but, as we shall see, I do not necessarily agree. Gorelick's account is interesting and a good point of departure for an informed discussion on the issues in question, but as an account of theoretical science, I am not convinced. Let me, very briefly, draw attention to what I see as some of the shortcomings of Gorelick's account.

After considering a number of alternative accounts, Gorelick settles on hypothesis formation as the mark of theoretical science:

Hypothesis formation, where a hypothesis is a simple declarative statement, seems to be an unambiguous definition of theory. (Gorelick, 2011:7)

The problem here is that the definiendum itself is ambiguous. We have "theory" in the sense of "a scientific theory" and "theory" in the sense of "the theoretical portion of the scientific endeavour". These two usages are clearly linked, but it is also plausible that the two usages can come apart. It is thus a mistake to seek a single definition of "theory". We need to first disambiguate the question we're trying to answer. This ambiguity manifests itself in a couple of places in Gorelick's paper. For instance, the passage just quoted is a response to a remark by Patrick Suppes (1967). But Suppes would appear to be speaking of theory in the first sense, while Gorelick, is thinking of it in the second. Gorelick is simply not engaging with the issues Suppes is concerned with. Part of the reason for this is that Gorelick takes the question of what a scientific theory is to have been settled by Popper (1959), and Gorelick's main focus is the further question of distinguishing theoretical science from the rest. But Popper's attempt at demarcating scientific theories from non-science or pseudo-science (the so-called "demarcation problem") in terms of falsifiable hypotheses is generally thought to have failed.

Popper was moved to falsifiability as the criterion of a scientific theory by the thought that any number of experiments typically cannot conclusively confirm a single hypothesis, but a single experiment may serve to falsify a hypothesis. Duhem (1954), Lakatos (1970) and Quine (1980 [1951]), however, have all argued that a single hypothesis cannot be falsified either. The problem is that whenever experimental results conflict with the hypothesis under investigation, one can always shift the blame to auxiliary hypotheses (Colyvan and Ginzburg 2003). Rarely, if ever, can one isolate a single hypothesis to test. As Quine puts it "our statements about the external world face the tribunal of sense experience not individually but only as a corporate body" (Quine 1980 [1951]: 41). Sometimes, we even dismiss data (as outliers) because they fail to conform to the relevant hypothesis. Of course there is much more to 
say about this issue but there are overwhelming reasons to believe that, for all its intuitive appeal, Popper's attempted demarcation of science from pseudo-science fails.

This is relevant to Gorelick's paper because it is assumed that Popper has definitively answered the question of what a scientific theory is. Moreover, Gorelick's answer to the question of what theoretical science is rides on Popper's coat tails. If one were to accept Popper's response to the demarcation problem, Gorelick's account of theoretical science would seem very natural. Unfortunately, the former fails and this undermines much of the intuitive support for the latter. Modern accounts of scientific theories place less emphasis on the demarcation problem that Popper was interested in and focus more on what a theory is. Here the semantic account currently enjoys widespread (but not unanimous) support. According to this account, a theory is a collection of models (Suppes 1960, Van Fraassen 1980, Suppe 1989, Chakravartty 2001). I would suggest that looking at recent work in philosophy of science on the nature of scientific theories (e.g. Godfrey-Smith 2006) would be a fruitful place to start in answering Gorelick's question.

Putting aside the associations with Popper and falsification, the most serious problem with Gorelick's proposed definition of theoretical science is that it is too narrow. It leaves out a great deal of what is clearly theoretical work. For instance, systematising and organising data may lead to the formulation of further testable hypotheses, but new hypotheses do not need to be the aim of the exercise. For instance, when Johannes Kepler took Tycho Brahe's data and systematised it in his famous three laws of planetary motion, Kepler was clearly doing theoretical work. Closer to home, Darwin, as Gorelick rightly notes, was an exemplar of a theoretician, yet a great deal of Darwin's work was aimed at explaining and organising existing data.

In short, systematisation, organisation, and explanation seem to be left out of Gorelick's account of theoretical science. Let's focus on explanation. It is interesting to note that some of the accounts of theory in Gorelick's tables mention explanation. Indeed, three of the six citations in Table 3 (Gorelick 2011: 4) explicitly mention explanation as an important component of theoretical work, yet Gorelick lists these three as "associating theory with hypothesis formation". For example Richard Lewontin remarks (cited in Table 3) that "we demand both prediction and explanation from a theory" (Lewontin 1963: 223). Lewontin is surely right about this and it is rather telling that Gorelick ignores the suggestion that theoretical work involves explanation. I should note that explanation and hypotheses formation are very different. One can formulate new hypotheses without having any idea of why the data falls the way it does. For example, someone may have no idea why the sun rises each morning, yet can formulate the hypothesis that the sun will rise tomorrow. On the other hand, one can make no new predictions, yet explain why the sun has risen each morning.

Perhaps Gorelick has a broader conception of what hypotheses are. Perhaps he takes hypothesis formation to include the explanatory tasks in science. But then we are just arguing at cross purposes. This raises an interesting issue of whether it is possible to define a term such as "theory" in isolation. We may need to simultaneously nail down a whole family of related terms such as "hypothesis", "prediction", "law", "explanation" and the like. Be that as it may, I think it is useful to distinguish prediction from explanation. Both are involved in theoretical science, and any account of what theoretical science is must make room for both.

Very often the work of systematising, organising and explaining involves mathematics. It is interesting to note that Gorelick dismisses an alternative account of theoretical science that has mathematics as the mark of the theoretical. While I too have some misgivings about such a mathematics-focused account, Gorelick's main argument against the "theoretical is mathematical" account is that key pieces of theoretical science, such as the work of Charles R. Darwin, are not mathematical. Indeed, Darwin, it seems, was not very knowledgeable about mathematics at all. Darwin, however, most definitely did not see mathematics as irrelevant to theoretical work.

I have deeply regretted that I did not proceed far enough at least to understand something of the great leading principles of mathematics, for men thus endowed seem to have an extra sense. (Charles R. Darwin 2010: 23)

Here Darwin suggests that great theoretical insights are available to those with a good grasp of mathematics. While Gorelick may be right that mathematics is not the mark of theoretical science, we shouldn't be too quick to dismiss mathematics as irrelevant to the question at hand. Perhaps mathematics plays a central role in systematising data and delivering explanations (Colyvan 2001) and even formulating new hypotheses via analogies (Ginzburg and Colyvan 2004, Colyvan and Ginzburg 2010).

Gorelick's discussion represents a good start on the question of what theory is. But the final definition offered is too restrictive. The focus on hypothesis formation fails to recognise the rich and varied activities that constitute theoretical science. It also seems to rest on a faulty conception of how to distinguish science from non-science. Notice that I am not offering an alternative account of my own here. That is because I do 
not have one. I think the question that Gorelick's paper poses is difficult. But it is definitely one worthy of further work and I look forward to seeing such work.

\section{References}

Chakravartty, A. 2001. The semantic or model-theoretic view of theories and scientific realism. Synthese 127: 325-45. CrossRef

Colyvan, M. 2001. The indispensability of mathematics. Oxford University Press, Oxford. CrossRef

Colyvan M. and L.R. Ginzburg. 2003. Laws of nature and laws of ecology. Oikos 101: 649-53. CrossRef

Colyvan, M. and L.R. Ginzburg. 2010. Analogical thinking in ecology: looking beyond disciplinary boundaries. Quarterly Review of Biology 85: 171-82. CrossRef

Darwin, C.R. 2010. The Autobiography of Charles Darwin. Pacific Publishing Studio, Seattle.

Duhem, P. 1954 [1906]. The aim and structure of physical theory. Princeton University Press, Princeton.

Ginzburg, L.R. and M. Colyvan. 2004. Ecological orbits: how planets move and populations grow. Oxford University Press, New York.

Godfrey-Smith, P. 2006. The strategy of model-based science. Biology and Philosophy 21: 725-740. CrossRef
Gorelick, R. 2011. What is theory? Ideas in Ecology and Evolution. 4: 1-10. CrossRef

Lakatos, I. 1970. Falsification and the methodology of scientific research programmes. Pages 91-195 in Lakatos, I. and A. Musgrave, editors. Criticism and the growth of knowledge. Cambridge University Press, Cambridge.

Lewontin, R.C. 1963. Models, mathematics and metaphors. Synthese 15: 222-244. CrossRef

Popper, K.R. 1959 [1934]. The logic of scientific discovery. Hutchinson and Co., London.

Quine, W.V. 1980 [1951]. Two dogmas of empiricism. Pages 20-46 in Quine, W.V. From a logical point of view. 2nd edition. Harvard University Press, Cambridge, MA.

Suppe, F. 1989. The Semantic conception of theories and scientific realism. University of Chicago Press, Chicago.

Suppes, P. 1960. A comparison of the meaning and uses of models in mathematics and the empirical sciences. Pages 10-23 in Suppes, P. 1969. Studies in the methodology and foundations of science: selected papers from 1951 to 1969 . Kluwer Academic Publishers, Dordrecht.

Suppes, P. 1967. What is a scientific theory? In Morgenbesser, S., editor. Philosophy of science today. Basic Books, New York.

Van Fraassen, B.C. 1980. The Scientific image. Clarendon Press, Oxford. CrossRef 